\title{
STATIC AND DYNAMIC TESTS OF THE RAILWAY SUBGRADE CONSTRUCTION MODEL
}

The presented paper deals with the research of railway subgrade construction. The purpose was to compare static and dynamic modulus of deformation namely on two different railway subgrade constructions. The effect of reinforcing geosynthetics was found out as well, when a different type of reinforcing geosynthetics was used.

\section{Introduction}

In railway engineering the use of reinforcing geosynthetics plays more and more important role. It should either strengthen the whole railway subgrade construction or reduce the thickness of sub - base layer which would otherwise be required. However, the positive or negative response of the construction under the reinforcing has not been shown in the contemporary specifications so far.

Deformation characteristics are the base of the designing of the railway subgrade construction at ŽSR. Our approach consisted in carrying out of static and dynamic loading tests. Their results are the deformation characteristics aiming to verify the effect of two different reinforcing geosynthetic materials in the railway subgrade construction.

\section{Model measurements}

Model measurements took place at the Department of Railway Engineering since the year 2001 up to now. During this time a number of static and dynamic loading tests was carried out.

Two basic types of construction were proposed for making a comparison between type one and type two according to our determined criterions. They are described in section 2.2.

\subsection{The testing box description}

In order to carry out the considered trials there was built a testing box embedded to a concrete base to prevent a damage of its bottom created only by a steel plate in a relatively moderate thickness of $6 \mathrm{~mm}$ reinforced by transverse steel ribs. Further, it consists of a thin steel plate web in thickness of $3 \mathrm{~mm}$ partly reinforced by vertical angle reinforcement. The box is equipped with a beam serving as a support against the load which is allowed to vary its position namely in three different locations. Under the test the beam is fixed cross - above the box into two columns of the box. Two different places are tested on each position of the beam.

The scheme of the box which is $3400 \mathrm{~mm}$ long $1950 \mathrm{~mm}$ wide and $1200 \mathrm{~mm}$ high is shown in Fig. 1. There is a photo of the box in Fig. 2.

a)

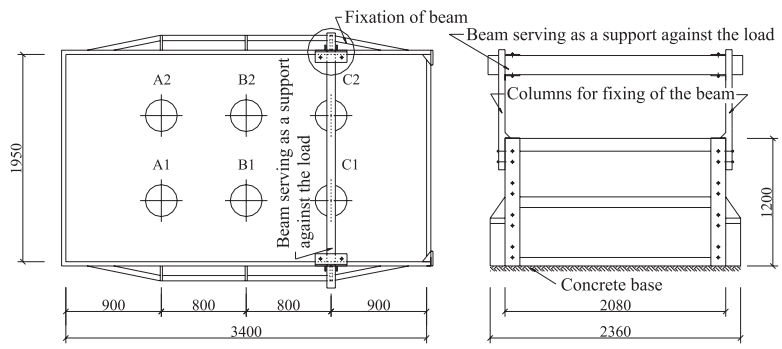

Fig.1 The scheme of the box with the localization of the static plate loading test sites

a) the plan view, b) the front - side view

\subsection{The testing constructions description}

As mentioned above two types of railway subgrade construction (Fig. 3) were tested. The basic part of construction consisted of the soft soil subgrade where this cohesive soil was classified in accordance with USCS as clay with intermediate plasticity (CI). In addition to this the main part of the construction was a sub base layer consisted of crushed rocks determined as soil $G P=$ poorly graded gravel within the coarser fractions of $0-32 \mathrm{~mm}$. These two basic materials were used for both type one and type two. The subgrade and the sub - base materials are very dissimilar and to not occur mechanism of soil fines pumping into aggregate voids or mechanism of aggregate particles intrusion into soil sub-

* Ing. Ján Lelak, Ing. Dušan Slávik, Ing. Martin Mečár

Department of Railway Engineering and Track Management, Faculty of Civil Engineering, University of Žilina, Komenského 52,01026 Žilina,

Slovak Republic, Tel.+421-41-7634818, Fax:+421-41-7233502, E-mail: jose@fstav.utc.sk, dslavo@fstav.utc.sk, mecar@fstav.utc.sk 


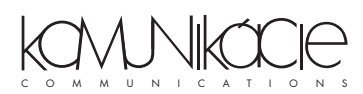

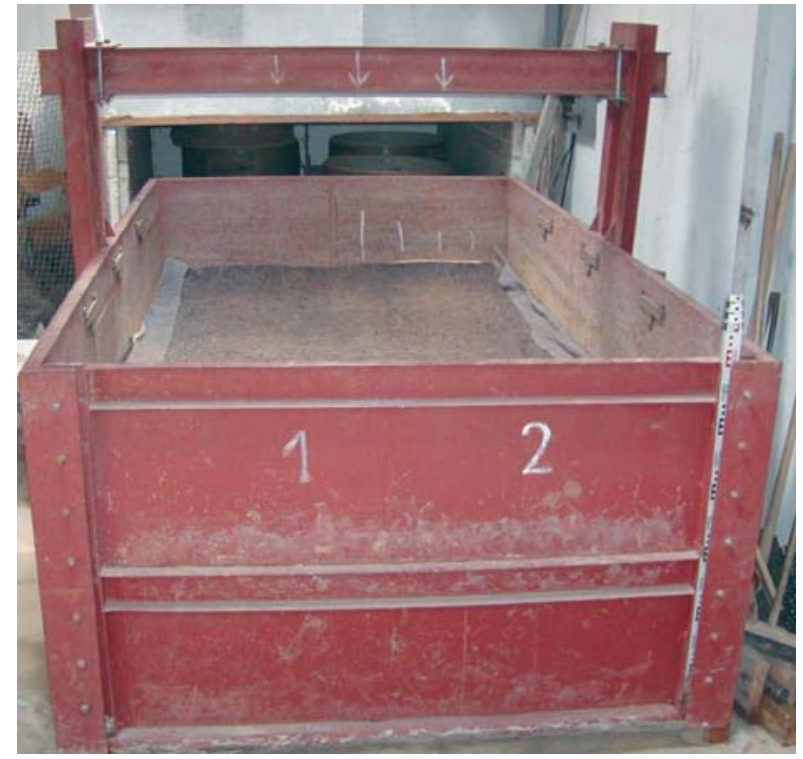

Fig. 2 Photography of the testing box at Department of Railway Engineering and Track Management

grade there had to be placed a suitable geotextile between those layers to separate them. That is why the integrity and functioning of both materials could remain intact or even be improved. In the case of type one there was used Macrit GTW/100 - 100. It is geocomposit consisting of the nonwoven geotextile and the reinforcing geogrid Arter GT. This member has both a separating effect (geotextile) and a reinforcing effect (geogrid). In the other case (type two) there was used a flexible porous separating textile Tatratex. The construction type two also included use of reinforcing geogrid Tensar SS30 laid down on the separating geotextile and away from the box webs in range of $100 \mathrm{~mm}$ to activate its function. a)

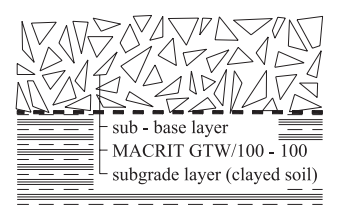

b)

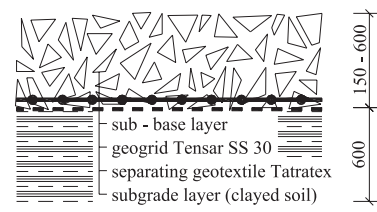

Fig. 3 The figure presents two types of railway subgrade construction the "type one", b) the "type two"

\subsection{The procedures of the model construction building}

The proper works were started by a constructing of the subgrade layer in completely thickness of $600 \mathrm{~mm}$, which was after finishing covered with Macrit or with the separating geotextile. Then there was gradually built the sub - base layer by parts of 300 , 450 and $600 \mathrm{~mm}^{1}$ ) (type one) and of 150, 300, 450, $600 \mathrm{~mm}^{1}$ ) (type two) (Fig. 3). It was determined that the thickness of free bagged loose gravelled material set by $10 \mathrm{~mm}$ on each $50 \mathrm{~mm}$ by compaction. The maximum value of thickness of the part - layer
$(150 \mathrm{~mm})$ resulted from a request of the maximum density in the whole sub - base layer. The thickness of every part - layer was controlled by levelling and then compacted with a step - power rammer Weber mt SRV 70 and a vibrating - plate - compactor ViDo 25/40.

\subsection{The performance of the loading tests}

Based on the results of the researchers considering the effect of reinforcing geosynthetics it is much more effective with lower values of the subgrade bearing capacity than its counterpart. That is why we needed to achieve that subgrade modulus of deformation ranging from 5 to $10 \mathrm{MPa}$. However, at the beginning we measured more than $10 \mathrm{MPa}$ and thus it was inevitable to adjust it. The clayed soil was mellowed and watered to reach its lower strength.

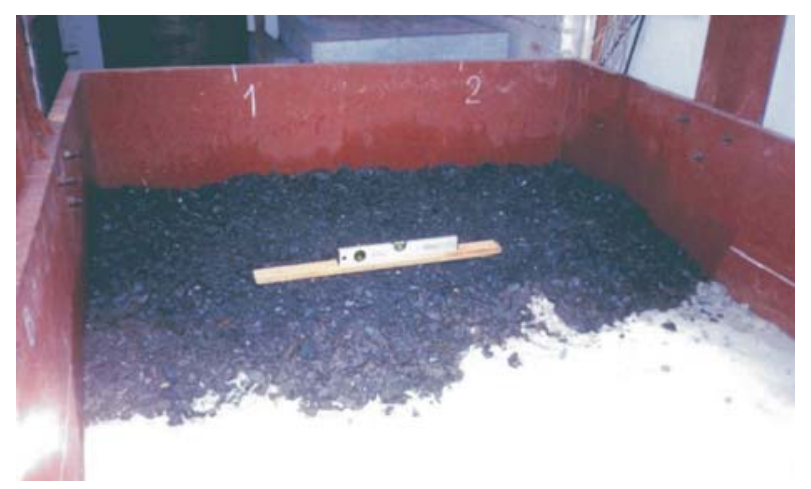

Fig. 4 Building of the sub - base layer of thickness of $150 \mathrm{~mm}$

The static loading tests (Fig. 5) were carried out with a plate in $300 \mathrm{~mm}$ diameter and evaluated in accordance with a railway guide of the subgrade S4 ŽSR [1]. There were performed 6 static loading tests on every part - layer (see 2.3 ) including the subgrade surface. They were performed after bagging and compaction in those places as marked in Fig. 1. Two loading cycles were generally realized during the test. The final value of modulus of defor-

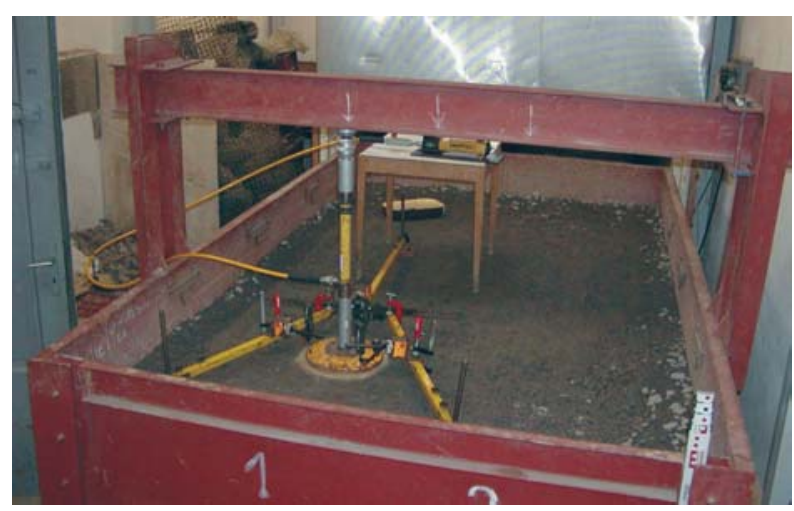

Fig. 5 Static plate loading test in the testing box 
mation was calculated from the maximum load $0.20 \mathrm{MPa}$ on the contact area (plate/soil) and from difference of plate deflections calculated from the maximum load of the second loading cycle and from the zero load taken off the end of the first loading cycle. The example of the static loading test record is presented in Fig. 6.

There were also performed 15 dynamic loading tests for a comparison between the static and the dynamic loading tests. The dynamic loading tests were carried out in accordance with the following method [4]: the measurement set was turned on after first impulse, which served for touch down of the plate $(300 \mathrm{~mm}$ diameter); then three impulses were applied and deflections of the plate were recorded. The maximum applied impulse force was $7.07 \mathrm{kN}$ and the impulse period was $18 \mathrm{~ms}$.

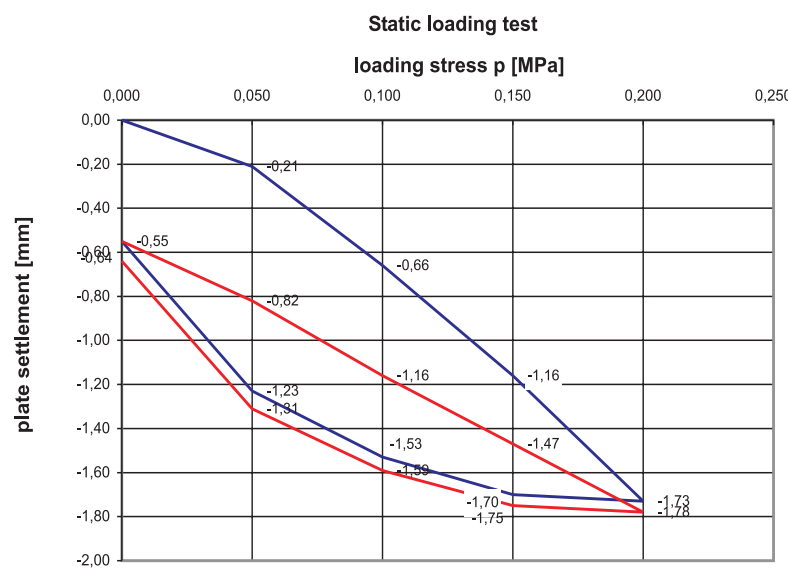

Fig. 6 The example of the static loading test record

\subsection{Evaluation of the measuring results}

After testing it was possible to calculate the numeric values of static modulus of deformation due to the equation (1).

$$
E=\frac{1.5 \cdot r \cdot \Delta p}{\Delta y}[\mathrm{MPa}]
$$

where $E$ - static modulus of deformation [MPa],

$r$ - loading plate radius $[0,15 \mathrm{~m}]$,

$\Delta p$ - loading stress [MPa],

$\Delta y$ - deflection related to loading stress [m],

and the numeric values of dynamic modulus of deformation due to the equation (2)

$$
E_{v d}=\frac{F}{d \cdot y_{e l}} \cdot\left(1-\mu^{2}\right)[\mathrm{MPa}]
$$

where $E_{v d}$ - dynamic modulus of deformation [MPa],

$y_{e l}-$ elastic deflection in the middle of the loading plate [mm],

$\mu$ - Poisson's number,

$F$ - loading force $[\mathrm{N}]$

$d$ - plate diameter $[\mathrm{mm}]$.

We calculated average values from the measured static and dynamic modulus of deformation which were arranged into the relation with thickness of sub - base layer by a simple function of $E=f(h)$. This relation is shown in graph no. 1 where are 4 curves representing both types of construction:

a) curve no. 1 shows this relation in the case of Macrit with the values of static modulus of deformation $\mathrm{E}$,

b) curve no. 2 shows similar relation with the difference of reinforcement, in this case by Tensar,

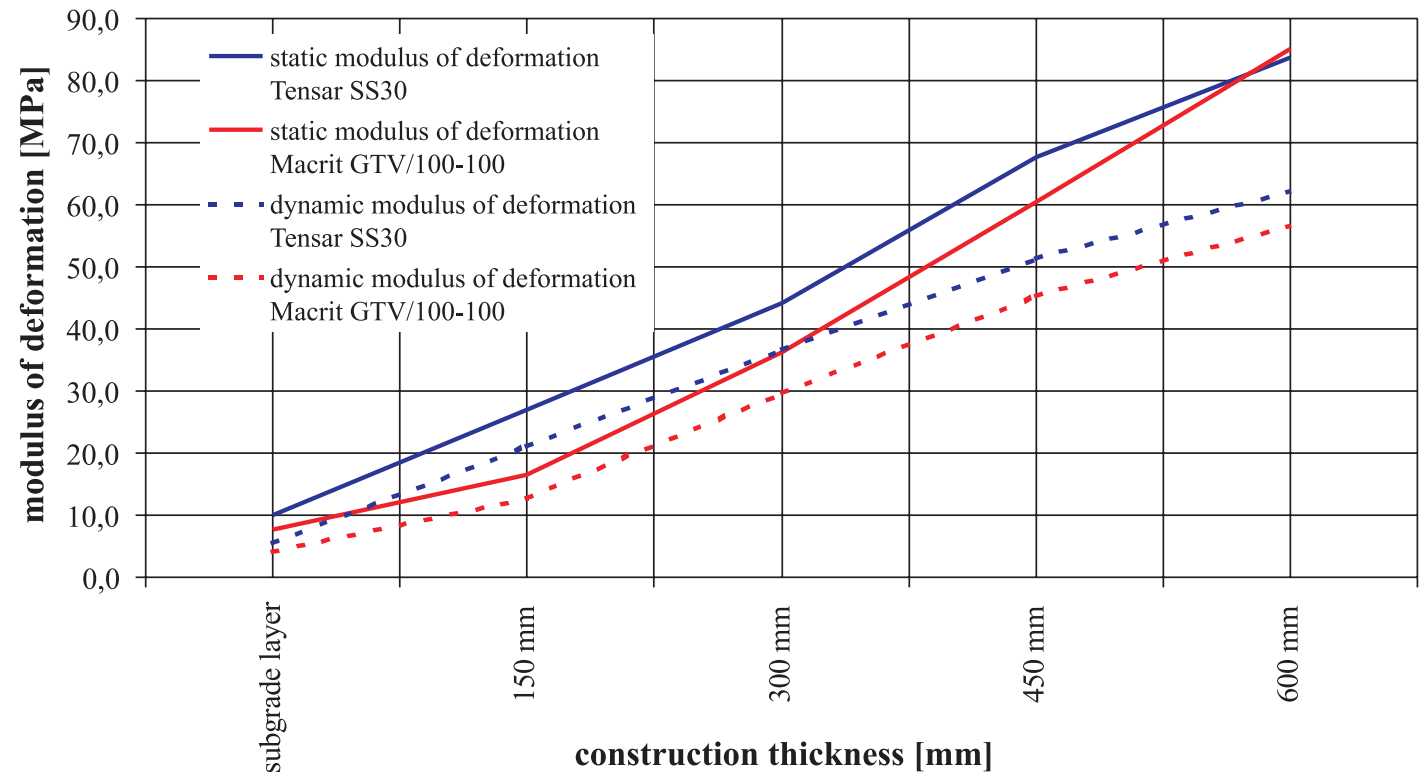

Graph 1 Relation between the values of static and dynamic modulus of deformation and the thickness of the sub - base layer 
c) curve no. 3 shows the relation with the dynamic modulus of deformation Evd in the case of Macrit,

d) and finally curve no. 4 includes the same relation in the case of the use of Tensar.

Owing to the results we could consider these following statements:

i) crushed rock material of fractions of $0-32 \mathrm{~mm}$ is suitable enough for sub - base layers in a railway subgrade construction [3],

ii) with the low bearing capacity of the subgrade there was observed substantially enormous increase of the bearing capacity after bagging and compaction of crushed rock material in the case of both Macrit and Tensar,

iii) the subgrade was still more and more compacted due to the building of the sub - base layer and thus it increased its bearing capacity (there was noticed two - times increase of its bearing capacity after excavation of the sub - base material unlike the initial measuring),

iv) a ratio between static and dynamic modulus of deformation had a falling tendency on the sub - base layers except the subgrade layer in both type one and type two,

v) a ratio between values of modulus of deformation (both static and dynamic)
Tensar/ Macrit gradually decreases with the increase of the layer thickness.

\section{Conclusions}

The present way of the checking of the railway subgrade construction increasingly tends mainly to applying of dynamic loading tests which are much faster than static loading tests and which represent greatly better the real behaviour of the construction. That is why we realized a set of the measurements of the static and the dynamic modulus of deformation with the aim of their mutual comparison but the current results do not allow generalization.

We suggest continuing in the model tests but with a better fraction $(0-63 \mathrm{~mm})$ of aggregates with a fluent particle size distribution than up to now. At the same time there would be needful to regard the moisture, Atterberg limits and particle size changes of both subgrade and sub - base material.

The research, which is presented in this paper, has been conducted under the project VE0GA 1/0341/03.

\section{References}

[1] Guide S4 ŽSR Railway subgrade, Nakladelství dopravy a spojů, Praha 1988

[2] LELAK, J.: Navrhovanie a posudzovanie konštrukcie podvalového podložia, Projekt dizertačnej práce, Žilina, 2002

[3] LELAK, J., SLÁVIK, D., MEČÁR, M.: The model measurements of the bearing capacity of the railway subgrade construction, 5-th European Conference of Young Research and Science workers in Transport and Telecommunications TRANSCOM 2003, Žilina, Slovak Republic, 23 - 25 June 2003

[4] The guide for service and use of light dynamic plate LDD 100 